\title{
Vancouver 2010 en stedelijke verdringing
}

AUTEUR \& FOTOGRAFIE Stephanie Sersli

De combinatie van stijgende prijzen voor onroerend goed, gentrificatie en de aanstaande Olympische Steden heeft bijgedragen tot de toename van dakloosheid en roept bezorgdheid op over het beeld dat Vancouver in 2010 van zichzelf aan de wereld zal tonen. De stad veegt daarom haar straten schoon.

In maart 2007 kwamen de inwoners van Vancouver er op een ochtend achter dat de Olympische vlag die op het stadhuis wapperde, was gestolen - juist op de dag dat er gedelegeerden van het Internationaal Olympisch Comité arriveerden om de voorbereidingen voor de Winterspelen van 2010 te evalueren. De gedelegeerden veroordeelden de actie direct. Volgens de Canadese pers zei Michael Chambers, de voorzitter van het Canadees Olympisch Comité: "Het is frustrerend dat iemand blijkbaar zo'n verwrongen beeld heeft van al het goede waar de Olympische Spelen voor staan, dat hij zoiets doet en daarmee volkomen onterecht de grootse historie van de Olympische Spelen beschadigt."

De groep die de verantwoordelijkheid voor de actie opeiste, verklaarde de volgende dag dat zij de vlag had verwijderd om aandacht te vestigen op "de verwoestingen die door de Winterspelen van 2010 veroorzaakt worden." Of men het nu eens is met de term 'verwoesting' of niet, het is onmiskenbaar dat het vooruitzicht van de Olympische Spelen de fysieke ontwikkelingen in Vancouver, Whistler en omstreken versnelt. De Olympische Spelen en de toch al bloeiende vastgoedmarkt in Vancouver resulteren samen in een concentratie van bouwactiviteiten. De vastgoedprijzen zijn de afgelopen tien jaar om verschillende redenen toch al drastisch gestegen, maar in juli 2003, nadat de voorzitter van het IOC Jacques Rogge bekend had gemaakt dat de Spelen van 2010 aan Vancouver waren toegewezen, stegen de verkoopcijfers van huizen onmiddellijk tot recordhoogte. In Vancouvers Downtown Eastside zijn de effecten daarvan duidelijk voelbaar.

\section{De strijd om de stedelijke ruimte}

Deze Olympische Spelen moeten worden gezien in het licht van de strijd over wie de stad kan claimen, in dit geval het oostelijke deel van Vancouvers stadscentrum. Hierbij zijn verschillende belangengroepen betrokken, zoals bewoners en zakenlieden, en spelen uiteenlopende ontwikkelingen een rol, waaronder ongelijke toegang tot middelen, de opkomst van Vancouver als 'wereldstad' en de tien jaar geleden in gang gezette gentrificatie.

Volgens de Franse filosoof Henri Lefebvre (1901-1991) is de fysieke ruimte altijd een weerslag van politieke verhoudingen. Hij maakte onderscheid tussen de alledaagse ervaren ruimte: het recht om er te wonen of er eenvoudigweg te zijn, en de abstracte ruimte: de economische waarde, oftewel de commerciële dimensie van stedelijke ruimte. In dit geval is er sprake van een belangentegenstelling tussen degenen die prijsstellen op de alledaagse geleefde ruimte, met al haar positieve en negatieve kanten, en partijen die er door middel van vastgoedhandel en speculatie winst mee willen behalen. In dit artikel wordt beschreven hoe dit conflict onlosmakelijk samenhangt met de ruimte. Er wordt onder andere stilgestaan bij de strikte controle op het gebruik van de ruimte, het streven naar 'toonbaarheid' en de uitoefening van macht ter bescherming van de abstracte ruimte, bijvoorbeeld met 


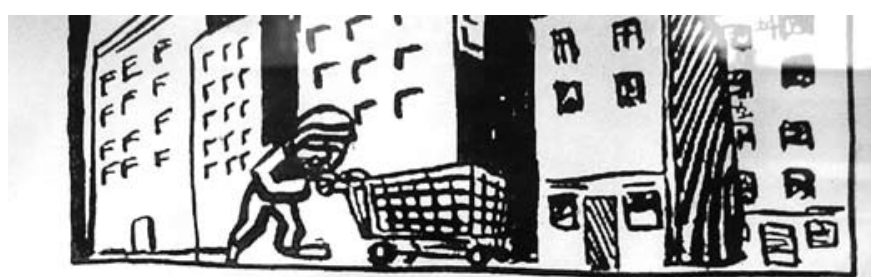

IS YOUR HOTIEI. THE NEXYT 'TO Cl.OSE?

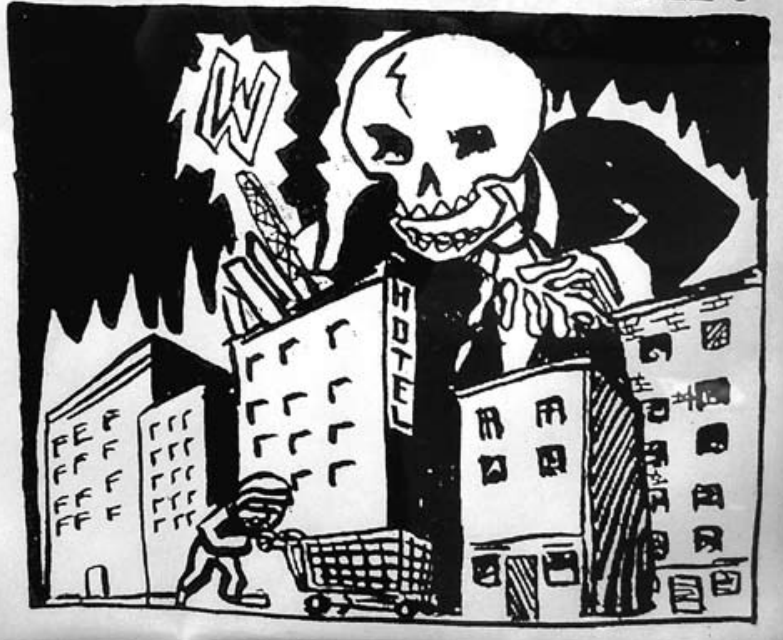

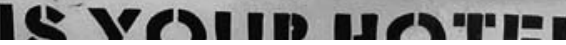

Figuur 1: "Is jouw pension het volgende dat sluit?" Poster voor het raam van de Downtown Eastside Resident's Association, Vancouver.

behulp van hekken en toezicht door politie en private beveiligingsbedrijven.

Downtown Eastside is een van de oudste wijken van Vancouver. Hoewel het niet de enige wijk met lage inkomens in deze stad is, staat Downtown Eastside bekend als 'Canada's armste postcodegebied'. De wijk heeft in het verleden voornamelijk lagere inkomensgroepen gehuisvest: seizoensarbeiders, alleenstaanden met laagbetaalde banen en nieuwkomers. Daarnaast was de wijk onder meer belangrijk voor de Indiaanse, Chinese en Japanse gemeenschap. Hoewel het om een relatief klein gebied gaat, is de bevolkingssamenstelling heel gevarieerd. Het merendeel van Vancouvers goedkope woningen is in deze wijk te vinden, evenals de hulpbronnen om in de stad te overleven. Algemene politieke en economische ontwikkelingen, zoals toename van de werkeloosheid, extramuralisering van (geestelijke) gezondheidszorg en bezuinigingen op de sociale zekerheid, hebben gevolgen gehad voor de wijk. Recentelijk nam ook het gebruik van harddrugs er zichtbaar toe, evenals het aantal daklozen. De wijk heeft met andere woorden te kampen met een grote sociale problematiek, maar kent tegelijkertijd een hechte gemeenschap. Dit blijkt onder meer door de vurige strijd die door bewonersorganisaties wordt gevoerd tegen sociaal onrecht (zie Figuur 1).

\section{Gevolgen van mega-evenementen}

Sinds 1988 zijn de vastgoedprijzen in Vancouver geleidelijk gestegen als gevolg van de investeringen van miljardair Li Ka-shing, die de voormalige Wereldtentoonstellingsterreinen opkocht en herontwikkelde, en de inspanningen van lokale en regionale politici, die door het aanhalen van de economische banden met Oost-Azië en Oceanië het imago van Vancouver hebben opgeschroefd van 'slaperige provinciestad' tot 'wereldstad'. Verlangen naar spectaculair vermaak, zoals Wereldtentoonstellingen en de Olympische Spelen, en het imago van een wereldstad gaan gewoonlijk goed samen met de financiële belangen van lokale en internationale handel, doordat zowel de zakelijke als sociale elite moeite wil doen om de internationale status van de stad in economisch en cultureel opzicht te vestigen en te behouden. Het resultaat van deze promotie was de toestroom van Canadees en internationaal kapitaal, de snelle ontwikkeling van woonruimte in het stadscentrum in de jaren negentig en een gestage afname van de betaalbaarheid van de huizen in heel Vancouver. In Downtown Eastside is het effect daarvan goed merkbaar. Het gebied ligt dicht bij de voormalige Wereldtentoonstellingsterreinen en is relatief goedkoop in vergelijking met de omringende stadsdelen. Bovendien ligt het centrum van Vancouver op een schiereiland, waardoor er behalve naar het oosten weinig ruimte is voor uitbreiding. De Pivot Legal Society, een juridische non-profitorganisatie, wijst erop dat steden onder meer met elkaar concurreren om het binnenhalen van de Spelen omdat zo'n evenement kansen biedt voor stedelijke herontwikkeling. Met name binnensteden kunnen daarvan profiteren. In het Inner-City Inclusive Commitment Statement, dat door het bid comité op de officiële website voor Vancouver 2010 is gepubliceerd, staat dat men ernaar streeft om de kansen die de Winterspelen de stad bieden optimaal te benutten en de eventuele negatieve gevolgen voor het centrum te beperken. Hoe dit gerealiseerd zou moeten worden, wordt echter niet duidelijk. Er staan weliswaar aanbevelingen op de site van de Inner-City Inclusive Housing Table (een commissie van afgevaardigden van verschillende bewonersverenigingen), maar het is nog maar de vraag of deze ook worden geïmplementeerd.

Het Commitment Statement moet worden gezien binnen de context van de reeds oprukkende gentrificatie en speculatie. De belangen en het enthousiasme van projectontwikkelaars, binnenstedelijke vastgoedeigenaren en middenklasse consumenten worden daarin veelal gelijkgesteld aan het welzijn van de gehele stad. De strijd rond de revitalisering van de oostzijde van de binnenstad is al jaren gaande en daarin staan de conflicten tussen verschillende sociale groeperingen en de ondernemersverenigingen van de buurten Gastown en Chinatown centraal. Een voorbeeld waaruit de botsende belangen blijken van ondernemers en daklozen is de succesvolle lobby van Gastowns ondernemersvereniging bij de lokale overheid om het bedelen te verbieden. Bovendien hebben de samenwerkende ondernemers beveiligingspersoneel ingehuurd om in de straten te patrouilleren en daklozen er onder meer van te weerhouden om in de buurt op straat te slapen.

\section{Goedkope huisvesting}

Hoewel de gentrificatie al in gang was gezet, bracht het vooruitzicht van de Olympische Spelen de ontwikkelingen in Downtown Eastside in een stroomversnelling. Tussen 1995 en 2005 zijn bijvoorbeeld 1206 nieuwe woningen gebouwd, met name in Gastown, en daarvan ruim 
350 in het laatste jaar. Eind 2006 was het aantal nieuwe woningbouwprojecten bijna verdrievoudigd. In datzelfde jaar waren alle 356 woningen die gepland waren op de locatie van het oude warenhuis Woodward's binnen twaalf uur verkocht: goed voor meer dan 200 miljoen dollar (130 miljoen euro) aan vastgoed in één dag! De aankoop en sloop van het al tien jaar leegstaande pand van Woodward's door de gemeente verbeeldt op krachtige wijze de revitalisering die het gebied momenteel ondergaat. De nieuwe appartementen, die in 2009 opgeleverd zullen worden, werden aan de man gebracht onder het mom van hip wonen in het 'spannende' oostelijke stadscentrum.

De ontwikkeling van luxe appartementen draagt bepaald niet bij aan de betaalbaarheid van de woonruimte in deze door hardnekkige armoede en dakloosheid geteisterde wijk. Om te kunnen voldoen aan de woonbehoefte van haar laagste inkomensgroepen zijn volgens de berekeningen van de gemeente jaarlijks achthonderd nieuwe goedkope woningen nodig om een tegenwicht te kunnen bieden aan gentrificatie, bezuinigingen op de sociale voorzieningen en het gebrek aan alternatieve woonruimte elders in Vancouver. Met de Spelen in het vooruitzicht is de speculatiedrift echter groot - tussen 2003 en 2006 zijn de prijzen voor huizen en grond bijna verdubbeld - en dat wekt weinig vertrouwen dat de bewoners in de lagere inkomensklassen aan huurstijgingen of huisuitzetting zullen ontkomen. De goedkope woningvoorraad groeit namelijk niet, maar krimpt. Woningen die van oudsher geschikt waren voor de armere eenpersoonshuishoudens worden in een veel hoger tempo aan de voorraad onttrokken dan bijgebouwd. Tussen 2003 en 2005 verloor Vancouver netto 415 woningen in deze categorie, en tussen juni 2005 en juni 2006 verdwenen er door samenvoeging, huurstijging en renovatie nog eens vierhonderd.

De gemeente erkent het belang van huisvesting voor de laagste inkomensgroep. Dit type woningen is doorgaans de laatste optie die een individu heeft om dakloosheid te voorkomen. Daarom werd in 2003 een verordening van kracht die de conversie van goedkope appartementen in andere type woonruimtes reguleert. Eigenaren moeten nu een vergunning hebben voor sloop of aanpassing en door de aanvragen goed in de gaten te houden hoopt men de voorraad goedkoopste woningen in het gebied te beschermen en op peil te houden. Door deze regeling was de gemeente in staat om te berekenen dat in Downtown Eastside in 2007 netto 99 woningen uit het goedkoopste segment verloren zijn gegaan. Dit geeft echter geen volledig inzicht in wat er in het gebied gaande is, omdat de wooncomplexen die nog gerenoveerd worden, niet worden meegeteld. Het is echter geenszins gegarandeerd dat de mensen die er woonden na de renovatie terug kunnen keren en dan kan achteraf blijken dat er toch meer betaalbare woonruimte verloren is gegaan.

Wat betekent dit voor de bewoners die worden uitgezet? Het meest recente onderzoek toont aan dat de dakloosheid in Vancouver tussen 2002 en 2005 verdubbeld is, veelal als gevolg van gestegen woonlasten. Bovendien staat de resterende voorraad goedkope woningen onder druk. Met de Wereldtentoonstelling van 1986 in het vooruitzicht ontstond een grote vraag naar huisvesting, en huiseigenaren gingen toentertijd massaal tot uitzetting over, omdat zij aan toeristen en werknemers van het evenement veel meer konden verdienen. Voor de aanstaande Olympische Winterspelen verwacht men hetzelfde.
"De erfenis van mega-evenementen, zoals de Olympische Spelen en grote conferenties, is zeer negatief voor woongebieden en huisvesting." - Miloon Kothari, VN-verslaggever voor goede huisvesting

"De Olympische Spelen draaien om sport. Ze gaan niet over sociale problemen, het corrigeren van ervaren onrechtvaardigheid of het agenderen van andere beleidsprioriteiten. Sommige actievoerders proberen daar weliswaar de aandacht op te vestigen, maar zonder succes." - Redactioneel Vancouver Sun, 12 februari 2008

Verrassend genoeg werd in april 2007 bekend dat het provinciebestuur van Brits-Columbia tien goedkope pensions had opgekocht in het oostelijke deel van het stadscentrum. Deze aankoop moest voorkomen dat ze door gretige projectontwikkelaars zouden worden verbouwd tot duurdere onderkomens. In plaats daarvan blijven ten minste 595 betaalbare kamers behouden en hopelijk worden ze ook opgeknapt. In februari 2008 kocht de provincie nog eens zes pensions met in totaal 330 kamers. Hoewel dit door velen wordt gezien als een stap in de goede richting, verkleint dit het benodigde aantal goedkope woningen niet. De ernst van de situatie wordt geïllustreerd door het gestaag toenemen van de dakloosheidcijfers. Het aantal buitenslapers werd in 2007 geschat op 1500 tot 2000 en daarnaast verbleven er nog eens honderden in opvangcentra en op tijdelijke adressen. Naar verwachting van de gemeente zal dit aantal groeien tot 3000 in 2010. De provincie kondigde eind 2007 aan dat tegen die tijd alle opvangcentra in Brits-Columbia 24 uur per dag, zeven dagen per week geopend zullen zijn om de grote vraag aan te kunnen.

\section{Maatregelen voor een nette stad}

De gemeente heeft daarnaast bekendgemaakt dat ze voordat de Olympische Spelen in 2010 beginnen de straten in Downtown Eastside zal 'schoonvegen'. Burgemeester Sam Sullivan heeft in november 2006 aangekondigd dat hij in het kader van Project Civil City het bedelen, de straathandel in drugs en het aantal daklozen zal gaan bestrijden door meer politietoezicht en strengere wetshandhaving. Op zijn officiële website verklaart hij dat het buiten kijf staat dat er snel en daadkrachtig moet worden opgetreden om de sociale ongeregeldheden waar de stad onder lijdt, op te lossen. De Olympische en Paralympische Winterspelen zijn volgens hem een geweldige stimulans om die veranderingen in gang te zetten.

Dit denken in oplossingen voor 'sociale ongeregeldheden' kan in verband worden gebracht met het idee van 'esthetiek van de ruimte', waaraan volgens sociaal geograaf Don Mitchell iedere andere afweging, zoals de behoefte van daklozen om te eten, te slapen of eenvoudigweg op straat te zijn, ondergeschikt is. In deze ideologie wordt 


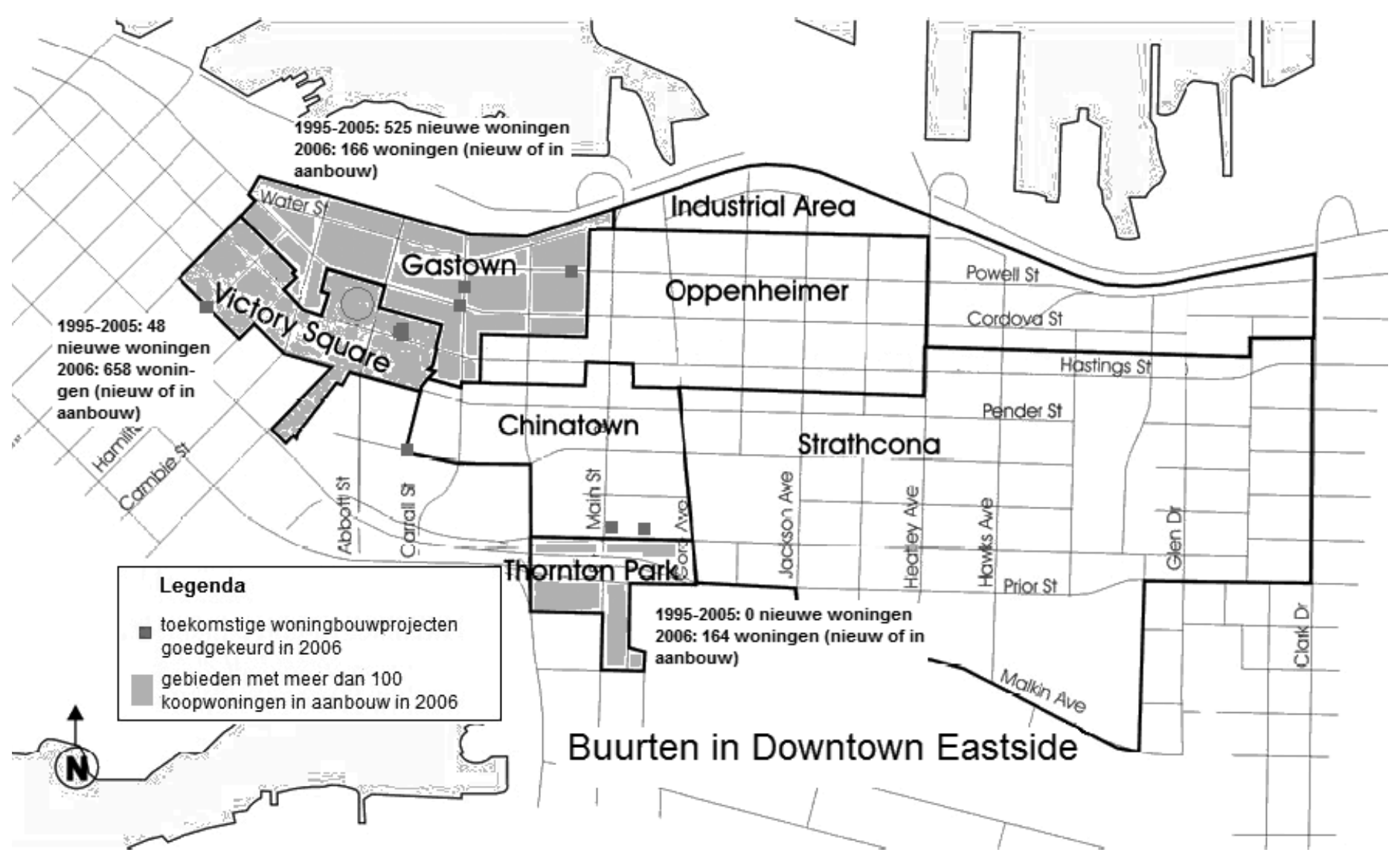

Figuur 2: Nieuwbouwprojecten in het centrum van Vancouver. (bron: City of Vancouver Downtown Eastside Community Monitoring Report (2006))

onroerend goed meer gewaardeerd dan mensen, moet de binnenstad koste wat het kost herontwikkeld worden en wordt Downtown Eastside niet beschouwd als een gemeenschap, maar als een geografisch gebied. Met de Olympische Spelen in aantocht hebben daklozen, verslaafden, armen en psychiatrisch patiënten om met Lefebvre te spreken geen recht meer op de stad, omdat zij niet de gewenste gebruikers zijn en geen positieve bijdrage leveren aan het straatbeeld. Men wil dat de straat een voorspelbare overzichtelijke omgeving is, waarin een beschaafd publiek de levendigheid van de stad kan ervaren. De zogenaamde ongeregeldheden en het verval van Downtown Eastside is onaantrekkelijk, en zij die vrezen dat het gebied onbehaaglijk zal zijn voor de Olympische toeristen beklagen zich dan ook over het gebrek aan surveillerende politie.

Het is niet de eerste keer dat de gemeente het politietoezicht in Downtown Eastside uitbreidt. In 2003 werd al eens een team van 67 agenten opgericht om korte metten te maken met criminaliteit, drugs en vernielingen. Er was niet alleen zichtbaar meer politie op straat, men surveilleerde ook in burger. Als gevolg daarvan werden daklozen en drugsdealers naar andere delen van de stad verjaagd. Het nieuwe Project Civil City stelt onder andere voor om de gemeentelijke schoonmaakdienst te trainen om criminele activiteiten te signaleren en te rapporteren aan de politie. Andere voornemens zijn het afsluiten van afvalbakken, inzet van meer handhavers van gemeentelijke verordeningen en het plaatsen van beveiligingscamera's.

Hoewel er geen Olympische sportfaciliteiten in Downtown Eastside worden gerealiseerd, zijn er in het gebied talloze ontwikkelingslocaties en bouwprojecten. De combinatie van stijgende vastgoedwaarden, gentrificatie en de aanstaande Olympische Spelen heeft bijgedragen aan stijgende dakloosheidcijfers en bezorgdheid over het beeld dat de wereld in 2010 van Vancouver zal krijgen. Welk schouwspel zal de bezoekers en de televisiecamera's worden voorgeschoteld?

\section{Stephanie Sersli (sersli@yorku.ca) is bezig met de afronding} van haar master Geografie aan de York Universiteit in Toronto, Canada. Zij woont in Vancouver op loopafstand van Downtown Eastside. Vertaald door Jesper van Loon en Martijn van der Linden.

\section{Literatuurselectie}

Lefebvre, H. (1991) The production of space. Malden: Blackwell Publishing. Lowes, M. (2002) Indy dreams and urban nightmares: speed merchants, spectacle, and the struggle over public space in the world-class city. Toronto: University of Toronto Press.

Mitchell, D. (2003) The right to the city: social justice and the fight for public space. New York: The Guildford Press.

Nielsen, L. (2007) Global Vancouver: spatial and temporal contestations in an emerging global city. Politics and Culture 2, 2. <aspen.conncoll.edu/ politicsandculture/> Laatst bezocht mei 2008.

Olds, K. (1998) Canada: hallmark events, evictions, and housing rights. In: A Azuela, E. Duhua \& E.Ortiz (eds) Evictions and the right to housing: experience from Canada, Chile, the Dominican Republic, South Africa and South Korea. IDRC.

Pivot Legal Society (2006) Cracks in the Foundation. Solving the housing crisis in Canada's poorest neighbourhood. Vancouver: Pivot Legal Society. 